\title{
Magnetic Susceptibilities of Oceanic Basalts in Alternative Fields
}

\author{
Mounir Trigui ${ }^{1}$ and Alain TABBAGH ${ }^{2}$ \\ ${ }^{1}$ ENIT, BP 37, Le Belvédère, 1002 Tunis, Tunisie \\ ${ }^{2}$ Centre de Recherches Géophysiques, C. N. R. S., 58150 Pouilly-sur-Loire, France
}

(Received August 11, 1989; Revised January 26, 1990)

\begin{abstract}
Susceptibility measurements were undertaken over 32 samples of oceanic basalts in weak uniform alternative field, in order to determine the variations of both in-phase and quadrature susceptibilities with frequency in the range $1 \mathrm{~Hz}-10 \mathrm{kHz}$.

Multidomain grain basalts exhibit variations clearly different from single domain and pseudo-single domain ones, but in most cases a decrease of the in-phase susceptibility with frequency is verified. Except for four samples the direct proportionality between quadrature susceptibility and the first derivative of the in-phase susceptibility with frequency logarithm is also experimentally observed.
\end{abstract}

\section{Introduction}

Basalts are the major constituents of the upper part of the oceanic crust. Their study brings much information about its history; the thermoremanent magnetization, in particular, has been and remains one of the main supports of the sea-floor spreading and plate tectonics theories (HEIRTZLER et al., 1968). It is important to obtain in situ measurements of the magnetic susceptibility of the basalts since this allows the determination of the natural remanent magnetization (DALY and TABBAGH, 1988) and also constitutes a very valuable source of information about the chemical and magnetic (grain size) state of the rock and its history (effects of weathering).

The measurement of the susceptibility $(\chi)$ in alternating fields, with electromagnetic devices of one or two coils, is simple and of common practice. Borehole logging with such magnetic susceptibility tools was the only way to obtain continuous and complete vertical profiles; it is not uncommon, in fact, in holes of DSDP and ODP programs, to have core recovery rates as low as 30\%. Many magnetic susceptibility measurements in alternating fields have been executed and published but there has been no exhaustive study with a well-calibrated apparatus and we have only very poor information about the frequency dependence of the modulus and of the phase of the susceptibility, which indeed has to be considered as a complex quantity:

$$
\chi=\chi_{\mathrm{p}}-i \chi_{\mathrm{q}}
$$

Only four studies have been published; one (VINCENZ, 1965) to develop theoretical conclusions; the second on basalts and artificial samples (BHATHAL and STACEY, 1969); the third on soils (MULLINS and TITE, 1973); the fourth (BLOEMENDAL et al., 1985) using the viscous magnetic behavior to demonstrate the existence of small grains, of size ranging near the superparamagnetic stable simple domain boundary. There has been no 
study on a sufficient number of oceanic basalt samples to clearly establish the behaviour of that type of rocks in weak time varying magnetic fields. Nevertheless $\chi$ may exhibit variations with frequency which must be taken into account when determining susceptibility in DC fields from AC field values (this is the case when using logged data) and there is a narrow link between these variations, the quadrature component of the susceptibility and the magnetic viscosity, all depending on the size of the magnetic grains. We present here a study of a set of 32 samples of oceanic basalts of miscellaneous origin over frequencies ranging from $1 \mathrm{~Hz}$ to $10 \mathrm{kHz}$ with an apparatus using a uniform primary field (which is necessary to define the absolute value of $\chi$ by reference to geometrical and electrical quantities) and delivering a good precision in the measurement of the phase lag between the primary field and the moment of the sample.

\section{Apparatus}

As is commonly the case for sinusoidal field measurements, the apparatus comprises a primary coil generating the inducting primary field and secondary coil which delivers a voltage proportional to the moment of the sample. To fit with the objective, geometrical conditions are the following:

- The primary field has to be uniform over the entire volume of the sample and the entire volume of the secondary coil.

- The secondary coil has to comprise two antisymmetrical parts in order to deliver the smallest response in the absence of a sample and to present a good rejection of the external magnetic variations.

- The sample is placed in the secondary coil such that the electrodynamic constant between the sample and the secondary coil is precisely defined, which means that the field which would be created by the secondary on the whole sample volume would be uniform.

Both circuits were constituted by a series of flat girdle coils with the same diameter so as to constitute solenoids, characteristics of which are presented in Fig. 1 for the primary and Fig. 2 for the low frequency secondary. The variations of the electromagnetic constants are shown on these diagrams by reference to the value at the centre of the solenoid for the primary and its value at the centre of one of the two antisymmetrical parts for the secondaries. Electrical conditions are more difficult to respect because it is difficult to simultaneously obtain a good precision on phase measurements, which requires staying below the resonance frequencies of the coils (less than a fifth), a good sensitivity with a high signal to noise ratio over a large frequency range $(10 \mathrm{kHz})$ and a limitation of the primary field intensity to a magnitude equivalent to that of the Earth's magnetic field. It was then necessary to build two devices having as nearly as possible the same characteristics but differing by the number of turns on each coil. The first apparatus was devoted to the $1 \mathrm{~Hz}-110 \mathrm{~Hz}$ frequency range (termed Lower Frequency Apparatus); the second for the $80 \mathrm{~Hz}-10 \mathrm{kHz}$ range (Higher Frequency Apparatus). The frequencies common to both apparatus allowed us to verify the good agreement between their responses. The electrical characteristics of both apparatus are presented in Tables 1 and 2.

This set of characteristics results from a compromise; the choice of each was discussed in detail by calculation and experiment (TRIGUI, 1987).

A transferometer (Schlumberger 1250) was used for both current supply and measurements. As it allows measurement on two channels and measurement of the 
Magnetic Susceptibilities of Oceanic Basalts in Alternative Fields
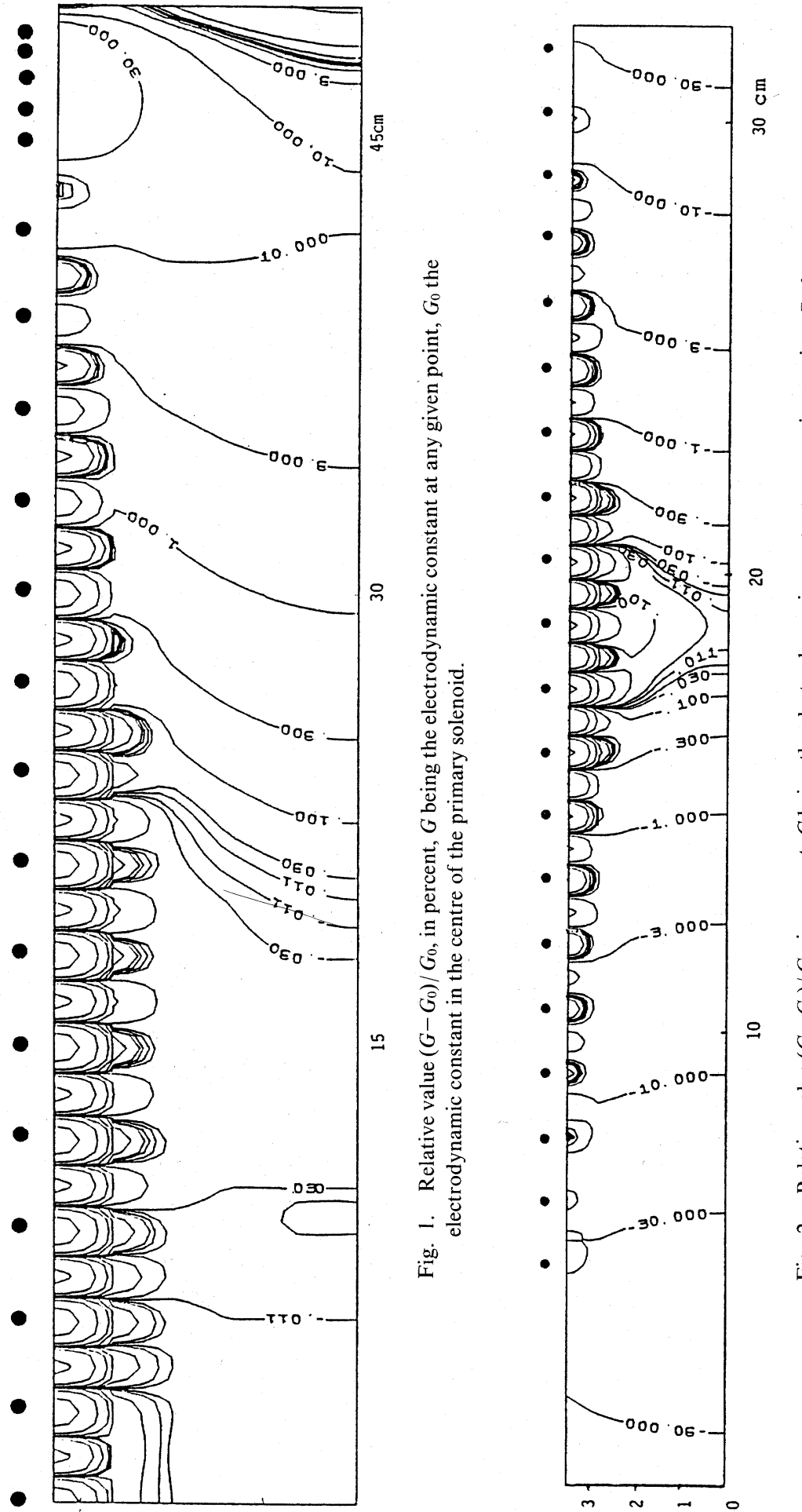

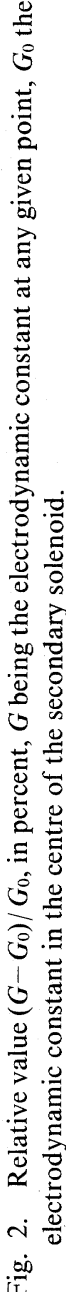

ó

6 
Table 1. Primary solenoids.

\begin{tabular}{lcc}
\hline $\begin{array}{l}\text { Number of turns } \\
\text { on each girdle coil }\end{array}$ & 20 & 50 \\
Number of girdle coils & 39 & 39 \\
Total resistance & $74.3 \Omega$ & $46.0 \Omega$ \\
Self inductance & $29.6 \mathrm{mH}$ & $165 \mathrm{mH}$ \\
$\begin{array}{l}\text { Stray capacitance } \\
\text { (including measuring cable) }\end{array}$ & $890 \mathrm{pF}$ & $21 \mathrm{nF}$ \\
Resonance frequency & $31 \mathrm{kHz}$ & $2.7 \mathrm{kHz}$ \\
Electrodynamic constant & $8.11 \times 10^{-4} \mathrm{SI}$ & $2.04 \times 10^{-3} \mathrm{SI}$ \\
\hline
\end{tabular}

Table 2. Secondary solenoids.

\begin{tabular}{lcc}
\hline & H.F. & L.F. \\
\hline $\begin{array}{l}\text { Number of turns } \\
\text { per each girdle coil }\end{array}$ & 20 & 2500 \\
$\begin{array}{l}\text { Number of girdle coils } \\
\text { for each part of the } \\
\text { solenoid }\end{array}$ & 30 & 20 \\
Resistance & $575 \Omega$ & $23.6 \mathrm{k} \Omega$ \\
$\begin{array}{l}\text { Self inductance } \\
\text { Stray capacitance } \\
\text { (including measuring cable) }\end{array}$ & $48.5 \mathrm{mH}$ & $87.4 \mathrm{H}$ \\
Resonance frequency & $772 \mathrm{pF}$ & $774 \mathrm{pF}$ \\
Electrodynamic constant & $26 \mathrm{kHz}$ & $612 \mathrm{~Hz}$ \\
\hline
\end{tabular}

amplitude ratio and phase differences between these two channels, it was possible to obtain on channel 2 the secondary voltage and on channel 1 the current crossing the primary. The main difficulty lies in phase measurement because we wished to determine with a precision of $10^{-5} \mathrm{SI}$ the quadrature susceptibility of a sample which can have an in-phase susceptibility reaching $5000 \times 10^{-5} \mathrm{SI}$, so we need a precision better than 0.01 degree. Such precision is displayed by the transferometer but it was necessary to calibrate in both amplitude and phase for each frequency both the primary and secondary solenoids. We used for that purpose two small coils having the same diameter as the samples and which were placed successively at the sample location. For the calibration of the primary these coils were used as receivers, for the calibration of the secondary they were used as transmitters. After calibration, the measurements were done with the following procedure for each frequency: 1) search for the minimum response by slight movement of the secondary; 2) measurement without the sample, with sample, and again without sample, thus allowing estimation of the possible drift of the apparatus. This procedure is satisfactory since it produced a very good agreement between the results 
from the HF and LF apparatus and between the results at any frequency and those with neighbouring frequencies.

\section{Description of the Samples}

We studied a set of 32 samples, obtained from four different sites:

.7 samples from site 417, holes 417A and 417D drilled during IPOD legs 51 and 52. Their average age is around $100 \mathrm{Ma}$ (BLEIL and SMITH, 1980).

.8 samples from site 395 , hole $395 \mathrm{~A}$ drilled during leg 45 , where the age of the oceanic crust is $7.2 \mathrm{Ma}$ (JOHNSON, 1978).

.7 further samples were taken during the submarine Cyamex Rise campaign on the East Pacific Ridge at $21^{\circ} \mathrm{N}$ latitude. These samples are less than 21,000 years old (SMITH, 1984).

- 10 samples are from the Geometep campaign, dredged along the East Pacific Ridge between $2^{\circ} \mathrm{N}$ and $20^{\circ} \mathrm{S}$ latitudes. Their age varies between 0 and $0.95 \mathrm{Ma}$ (SMITH, 1984).

The samples were arranged in three groups according to the magnetic grain size. The ratio $J_{\mathrm{rs}} / J_{\mathrm{s}}$, between the saturated remanent magnetization and the saturated magnetization is decreasing with the grain size and was used for sorting. The first group comprises samples for which $J_{\mathrm{rs}} / J_{\mathrm{s}} \geq 0.4$; in these samples the ferrimagnetic grains are mostly single domain (SD). They come from two sites: 14 from the East Pacific Ridge (7 from the Cyamex Rise campaign, 7 from Geometep), the two remaining being from the Western flank of the Mid-Atlantic Ridge (hole 395A). The second group comprises samples with $0.1 \leq J_{\mathrm{rs}} / J_{\mathrm{s}}<0.4$, with 5 samples from holes $417 \mathrm{~A}$ and $\mathrm{D}, 6$ samples from hole 395A and 3 from the East Pacific Ridge (Geometep); all are PSD (pseudomonodomain) grains. The last group, MD (multidomain) grains, have $J_{\mathrm{rs}} / J_{\mathrm{s}}<0.1$ comprising 2 samples with large grains from hole $417 \mathrm{D}$. The criterion we used, $J_{\mathrm{rs}} / J_{\mathrm{s}}$, is the most commonly adopted for basalts (SMITH, 1984), but the PSD group is probably a mixture of several types and low value of the ratio may also indicate the presence of very small single domain (BLgemendal, 1985) as is the case for soils (MUllins and TITE, 1973).

\section{Experimental Results}

Twelve examples of experimental results are presented in Appendix 1 with the use of figures. On the figures we show the experimental points and also the least squares curves fitting them. The behaviour of the samples differs between the three groups, but within each group differences may exist in the frequency dependence of $\chi_{\mathrm{p}}$, some samples having virtually no variation, others showing important differences.

Single domain grain basalts. The decrease of the in-phase susceptibility is linear with the logarithm of the frequency, $f$. For six samples a parabolic variation fits better than a linear one with the data. The average decrease is $-0.6 \%$ per decade but it can be zero or greater than $1 \%$. The quadrature susceptibility is practically independent of the frequency; when a small increase exists it is linear. The ratio $\chi_{\mathrm{q}} / \chi_{\mathrm{p}}$ ranges between 0 and $5 \%$. Table 3 summarizes the main characteristics obtained for each sample at the arbitrary frequency of $440 \mathrm{~Hz}$.

Pseudo single domain grain basalts. In most cases, the in-phase susceptibility has a parabolic decrease with $\log f$. For three samples, only a linear variation is more likely than a parabolic one. Variations are more important below $100 \mathrm{~Hz}$ than above. 
Table 3. Samples.

\begin{tabular}{|c|c|c|c|c|c|}
\hline & $J_{\mathrm{rs}} / J_{\mathrm{s}}$ & $\begin{array}{c}\chi_{\mathrm{p}}(440 \mathrm{~Hz}) \\
{\left[\times 10^{-4} \mathrm{SI}\right]}\end{array}$ & $\begin{array}{c}\chi_{\mathrm{q}}(440 \mathrm{~Hz}) \\
{\left[\times 10^{-4} \mathrm{SI}\right]}\end{array}$ & $\frac{\chi_{\mathrm{q}}(440 \mathrm{~Hz})}{\chi_{\mathrm{p}}(440 \mathrm{~Hz})}[\%]$ & $\left(\frac{\partial \chi_{\mathrm{p}}}{\partial \log f}\right) \times 10^{-4}$ \\
\hline \multicolumn{6}{|l|}{ 1st Group (SD) } \\
\hline \multicolumn{6}{|l|}{ CYAMEX } \\
\hline CYP 78-02-02 (1b) & 0.69 & $11.5 \pm 0.07$ & $0.29 \pm 0.07$ & 2.52 & +0.09 \\
\hline CYP 78-02-02 (3c) & 0.53 & $28.9 \pm 0.13$ & $0.80 \pm 0.11$ & 2.77 & +0.10 \\
\hline CYP 78-12-34 a & 0.69 & $13.1 \pm 0.12$ & $0.22 \pm 0.10$ & 1.68 & +0.05 \\
\hline CYP 78-12-35 a & 0.62 & $14.6 \pm 0.05$ & $0.32 \pm 0.19$ & 2.19 & +0.06 \\
\hline CYP 78-13-45 (1) & 0.54 & $11.5 \pm 0.09$ & $0.38 \pm 0.17$ & 3.30 & +0.04 \\
\hline \multicolumn{6}{|l|}{ GEOMETEP } \\
\hline A-33a $\left(1^{\prime}\right)$ & 0.49 & $70.1 \pm 0.02$ & $0.36 \pm 0.20$ & 1.94 & +0.23 \\
\hline A-38 (1) & 0.59 & $18.4 \pm 0.12$ & $0.53 \pm 0.08$ & 2.88 & +0.14 \\
\hline G-171 & 0.72 & $63.6 \pm 0.12$ & $1.28 \pm 0.10$ & 2.01 & +0.07 \\
\hline F-202a (1) & 0.64 & $19.3 \pm 0.31$ & $0.25 \pm 0.14$ & 1.30 & +0.04 \\
\hline $\mathrm{F}-204 \mathrm{a}\left(2^{\prime}\right)$ & 0.45 & $107.6 \pm 0.08$ & $0.33 \pm 0.12$ & 0.31 & +0.08 \\
\hline F-218 & 0.58 & $29.1 \pm 0.07$ & $0.10 \pm 0.11$ & 0.34 & +0.00 \\
\hline F-223C2 & 0.75 & $19.3 \pm 0.10$ & $0.50 \pm 0.05$ & 2.59 & +0.03 \\
\hline \multicolumn{6}{|l|}{ LEG 45} \\
\hline $395 \mathrm{~A}-64-2(58-60)$ & 0.52 & $32.0 \pm 0.09$ & $0.15 \pm 0.10$ & 0.47 & +0.02 \\
\hline $395 \mathrm{~A}-55-2(28-30)$ & 0.66 & $19.1 \pm 0.03$ & $0.09 \pm 0.33$ & 0.47 & +0.05 \\
\hline \multicolumn{6}{|l|}{ RISE } \\
\hline ALV914-2 (2) & 0.61 & $13.4 \pm 0.22$ & $0.12 \pm 0.24$ & 1.64 & +0.05 \\
\hline ALV920-6 & 0.66 & $8.8 \pm 0.07$ & $0.46 \pm 0.10$ & 5.23 & +0.06 \\
\hline \multicolumn{6}{|l|}{ 2nd Group (PSD) } \\
\hline \multicolumn{6}{|l|}{ LEG $51-52$} \\
\hline $417 \mathrm{~A}-42-1(18-20)$ & 0.29 & $176.5 \pm 0.13$ & $0.81 \pm 0.13$ & 0.46 & -0.09 \\
\hline 417D-22-6 (18-21) & 0.24 & $213.5 \pm 0.16$ & $1.19 \pm 0.07$ & 0.56 & -0.24 \\
\hline $417 D-28-7(42-45)$ & 0.15 & $221.9 \pm 0.05$ & $1.25 \pm 0.10$ & 0.56 & +0.03 \\
\hline 417D-41-6 (137-139) & 0.34 & $140.2 \pm 0.12$ & $1.29 \pm 0.06$ & 0.92 & -0.20 \\
\hline $417 \mathrm{D}-42-1(60-62)$ & 0.35 & $46.9 \pm 0.11$ & $1.46 \pm 0.09$ & 3.11 & +0.83 \\
\hline \multicolumn{6}{|l|}{ LEG 45} \\
\hline $395 A-61-2-(81-83)$ & 0.35 & $55.4 \pm 0.19$ & $0.37 \pm 0.15$ & 0.67 & -0.02 \\
\hline $395 A-64-1-(95-97)$ & 0.20 & $63.4 \pm 0.07$ & $0.47 \pm 0.08$ & 0.74 & +0.02 \\
\hline $395 \mathrm{~A}-32-1(107-109)$ & 0.16 & $60.3 \pm 0.24$ & $0.48 \pm 0.21$ & 0.80 & +0.05 \\
\hline $395 \mathrm{~A}-14-3-(140-142)$ & 0.23 & $46.7 \pm 0.14$ & $0.16 \pm 0.17$ & 0.34 & +0.02 \\
\hline $395 A-15-2-(65-70)$ & 0.26 & $81.4 \pm 0.17$ & $1.04 \pm 0.07$ & 1.28 & -0.02 \\
\hline $395 \mathrm{~A}-27-2-(20-22)$ & 0.37 & $29.2 \pm 0.10$ & $0.22 \pm 0.16$ & 0.75 & +0.09 \\
\hline \multicolumn{6}{|l|}{ GEOMETEP } \\
\hline $\mathrm{F}-213(1)$ & 0.17 & $154.7 \pm 0.05$ & $2.54 \pm 0.11$ & 1.64 & -0.14 \\
\hline $\mathrm{F}-223 \mathrm{~b} 1\left(2^{\prime}\right)$ & 0.15 & $261.7 \pm 0.12$ & $6.84 \pm 0.06$ & 2.61 & -0.22 \\
\hline A-33b & 0.27 & $372.6 \pm 0.05$ & $18.9 \pm 0.14$ & 5.07 & -0.07 \\
\hline \multicolumn{6}{|l|}{ 3rd Group (MD) } \\
\hline \multicolumn{6}{|l|}{ LEG $51-52$} \\
\hline 417D-32-2-(61-64) & 0.089 & $306.3 \pm 0.25$ & $3.27 \pm 0.05$ & 1.07 & -2.00 \\
\hline $417 \mathrm{D}-50-2-(65-67)$ & 0.035 & $427.6 \pm 0.08$ & $3.53 \pm 0.18$ & 0.83 & -1.46 \\
\hline
\end{tabular}


As in the preceding case, $\chi_{q}$ is practically independent of the frequency, the slope being very weak and regular. The ratio $\chi_{\mathrm{q}} / \chi_{\mathrm{p}}$ has the same order of magnitude as that for SD basalts (Table 3).

Multi-domain grain basalts. For these two samples the variation of $\chi_{\mathrm{p}}$ with $\log f$ is cubic. The magnitude of the susceptibility is higher than for the second group and $a$ fortiori the first one. The quadrature susceptibility decreases linearly with $\log f$ which is very different from the two other groups (Table 3 ).

\section{Conclusions}

This experimental study leads to two major conclusions:

There exists a weak but non-negligible quadrature susceptibility. The in-phase susceptibility decreases appreciably with the frequency. It is important to emphasize these two points because it is common practice when using susceptibility data obtained using alternating fields to neglect them and to identify the values with those which would be obtained in continuous fields, while a relative difference of more than $10 \%$ may in fact exist between the susceptibility at $10 \mathrm{kHz}$ and that at $1 \mathrm{~Hz}$, and the difference will be even more important between the $10 \mathrm{kHz}$ value and the continuous field value.

The in-phase susceptibility variation with frequency is simpler for SD and PSD grains than for MD grains, so it would be interesting to look at theoretical approaches to link these experimental results to the microscopic characteristics of the magnetic grains. The theories of NÉEL for dispersed monodomain grains (1949) and bulk magnetic materials (1950) predict a linear decrease of $\chi_{\mathrm{p}}$ with $\log f$. This phenomenon is the same as that of viscosity observed in a continuous field and it is linked with the temporal decrease of the viscous remanent magnetization $J_{\mathrm{R}}$, by the relation

$$
-\frac{\partial \chi_{\mathrm{p}}}{\partial \log (2 \pi f)}=\frac{1}{h} \cdot \frac{\partial J_{\mathrm{R}}}{\partial \log t}
$$

( $h$ being the field which generated the magnetization). A complete comparison with the viscosity in continuous fields will be the subject of a forthcoming paper but we may note that the average value of the frequency dependence, for the three groups, is within $1 \%$ of the value predicted by VINCENZ (1965).

In their work on soil properties, MULLINS and TITE (1973) compared the experimental values from three samples to the relation

$$
-\frac{\partial \chi_{\mathrm{p}}}{\partial \log (2 \pi f)}=\frac{2}{\pi} \chi_{\mathrm{q}}
$$

which can be deduced from Néel's single domain theory (see Appendix 2). This quantitative relation linking the two effects has to be compared to experimental data for the 32 basalt samples. For the single domain group there is a reasonable agreement with the independence of $\chi_{\mathrm{q}}$ on frequency, which is not the case for MD samples and this difference could be used as a criterion for distinguishing between SD and MD grains. Figure 3 shows the value of $\partial \chi_{\mathrm{p}} / \partial \log (2 \pi f)$ as a function of $(2 / \pi) \chi_{\mathrm{q}}$ at $100 \mathrm{~Hz}$ (in order to also take into account the non-linear variation samples). The different points are grouped 


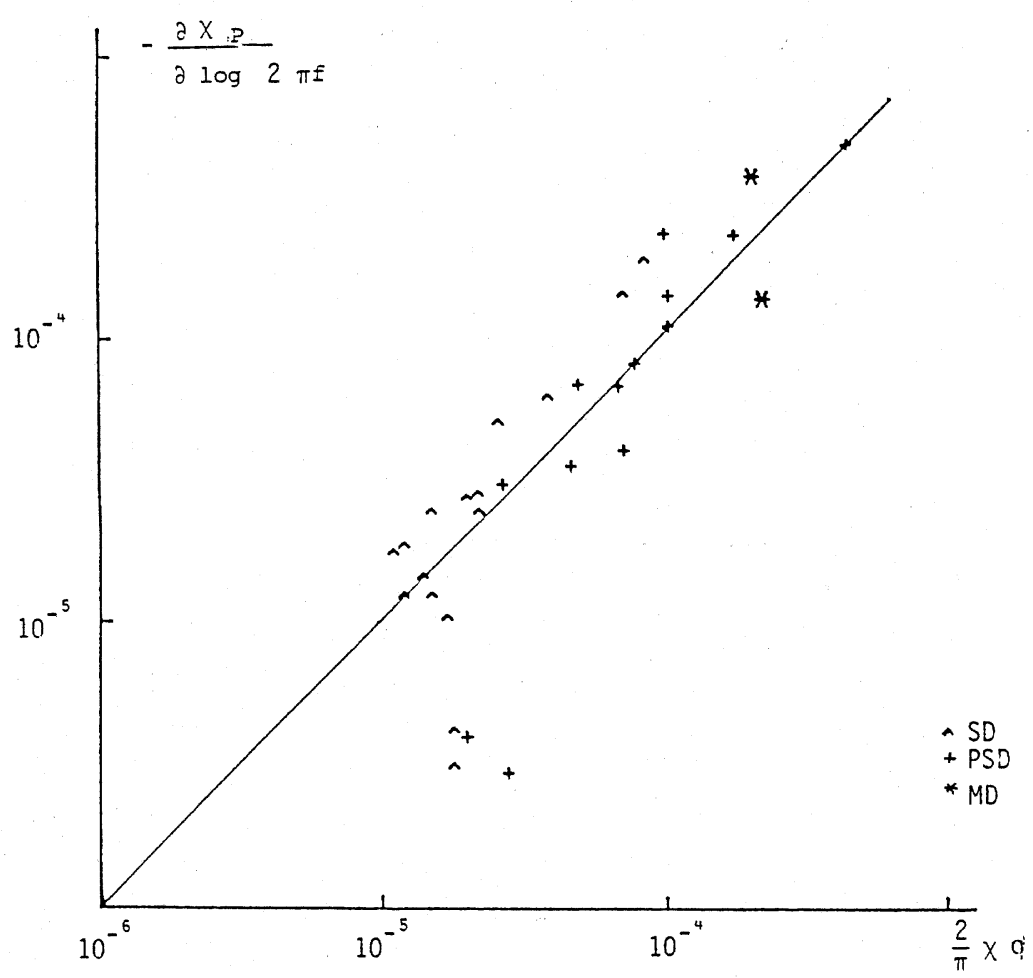

Fig. 3. Relation between $-\partial \chi_{\mathrm{p}} / \partial \log (2 \pi f)$ and $(2 / \pi) \chi_{\mathrm{q}}$.

in the neighbourhood of the $45^{\circ}$ slope straight line, there being only four exceptions corresponding to smallest values of $\chi_{\mathrm{q}}$. Two of these are from the PSD group, the others are from the SD group and we have no explanation for these rather surprising values. For the remaining 28 samples, the theoretical relation is roughly confirmed. This does not imply that all the magnetic behaviour of the samples we studied is in agreement with the single domain theory but suggests that this relation may be more general and would be true for several classes of rock magnetism theories. 
Appendix 1 .
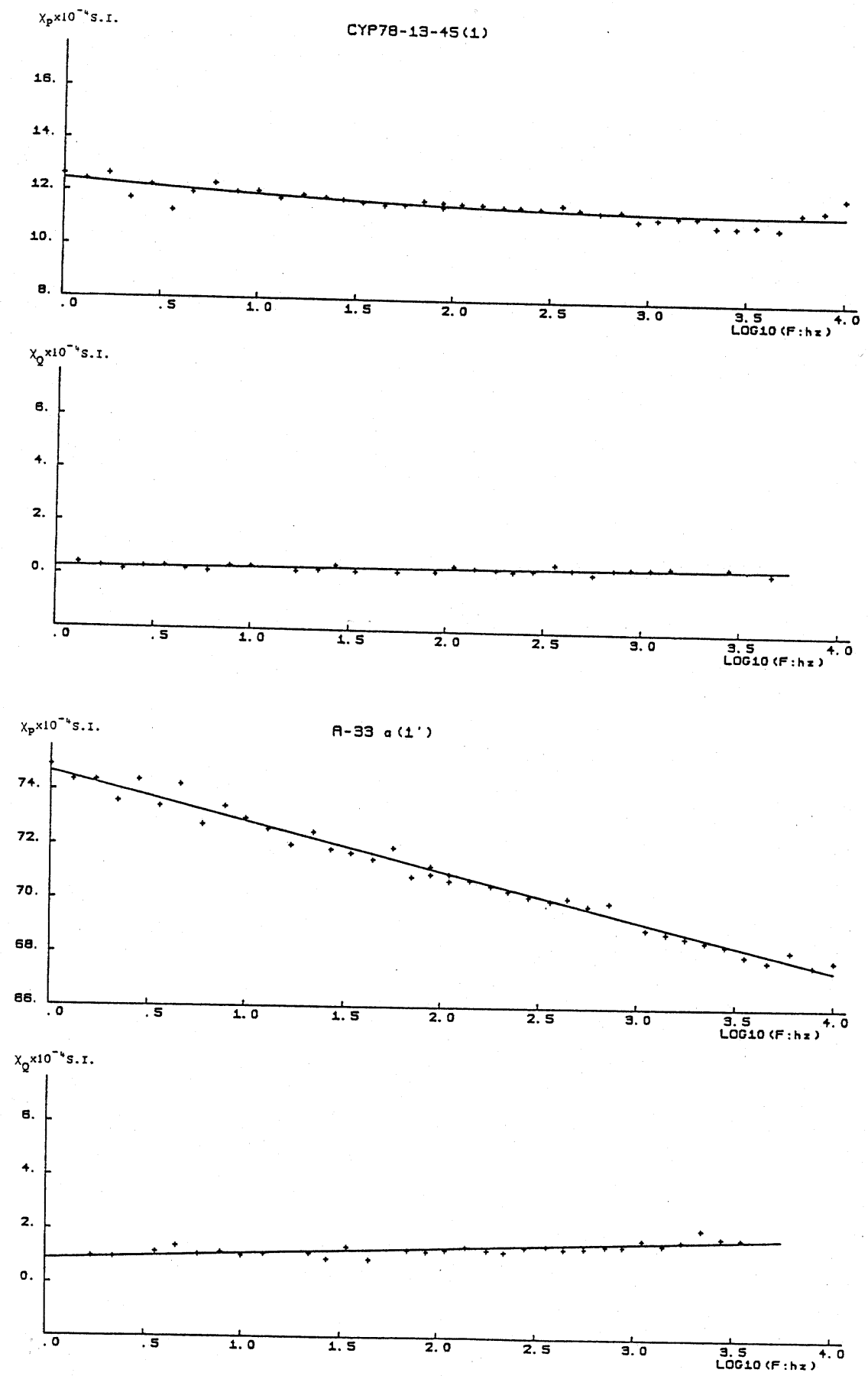

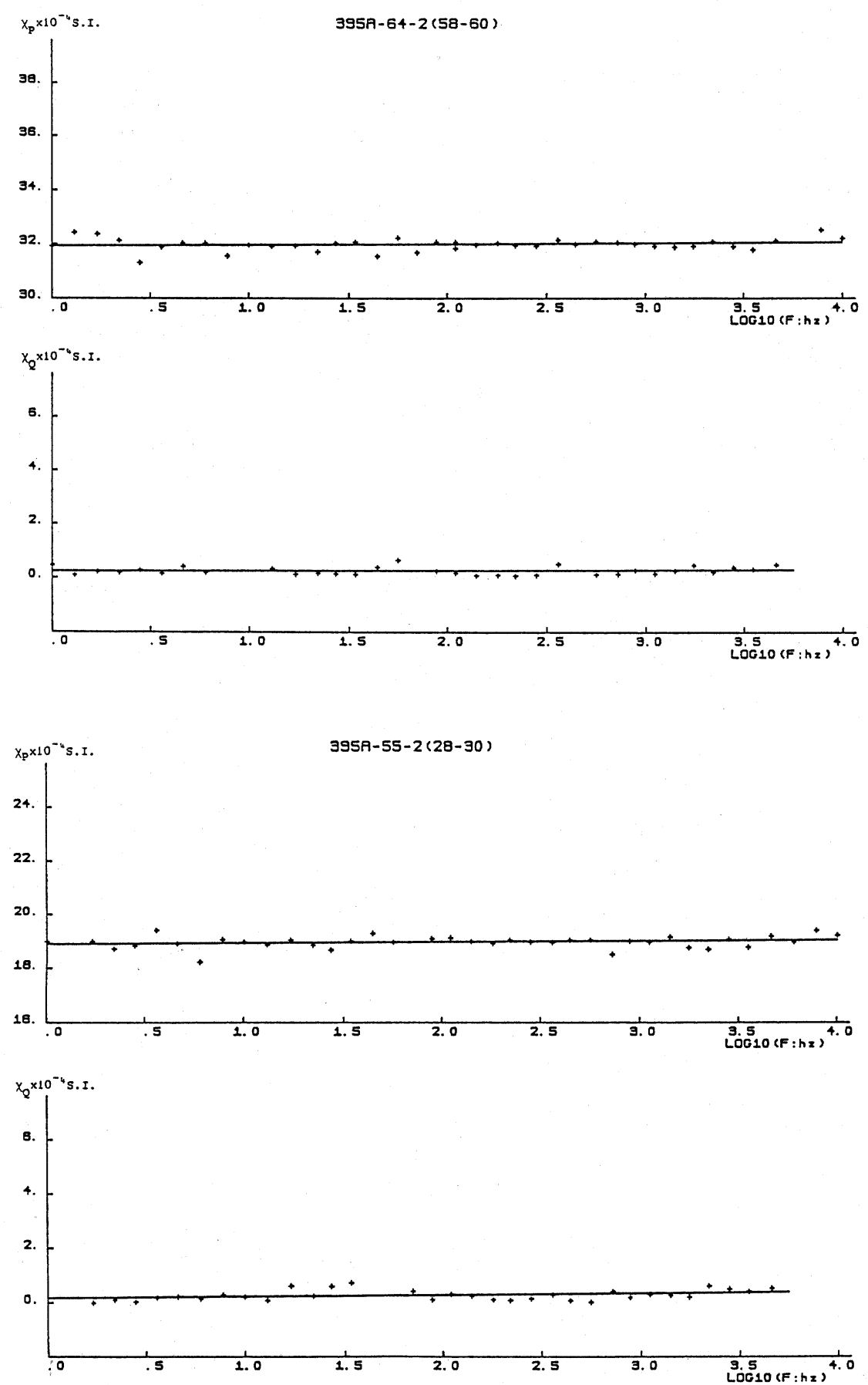

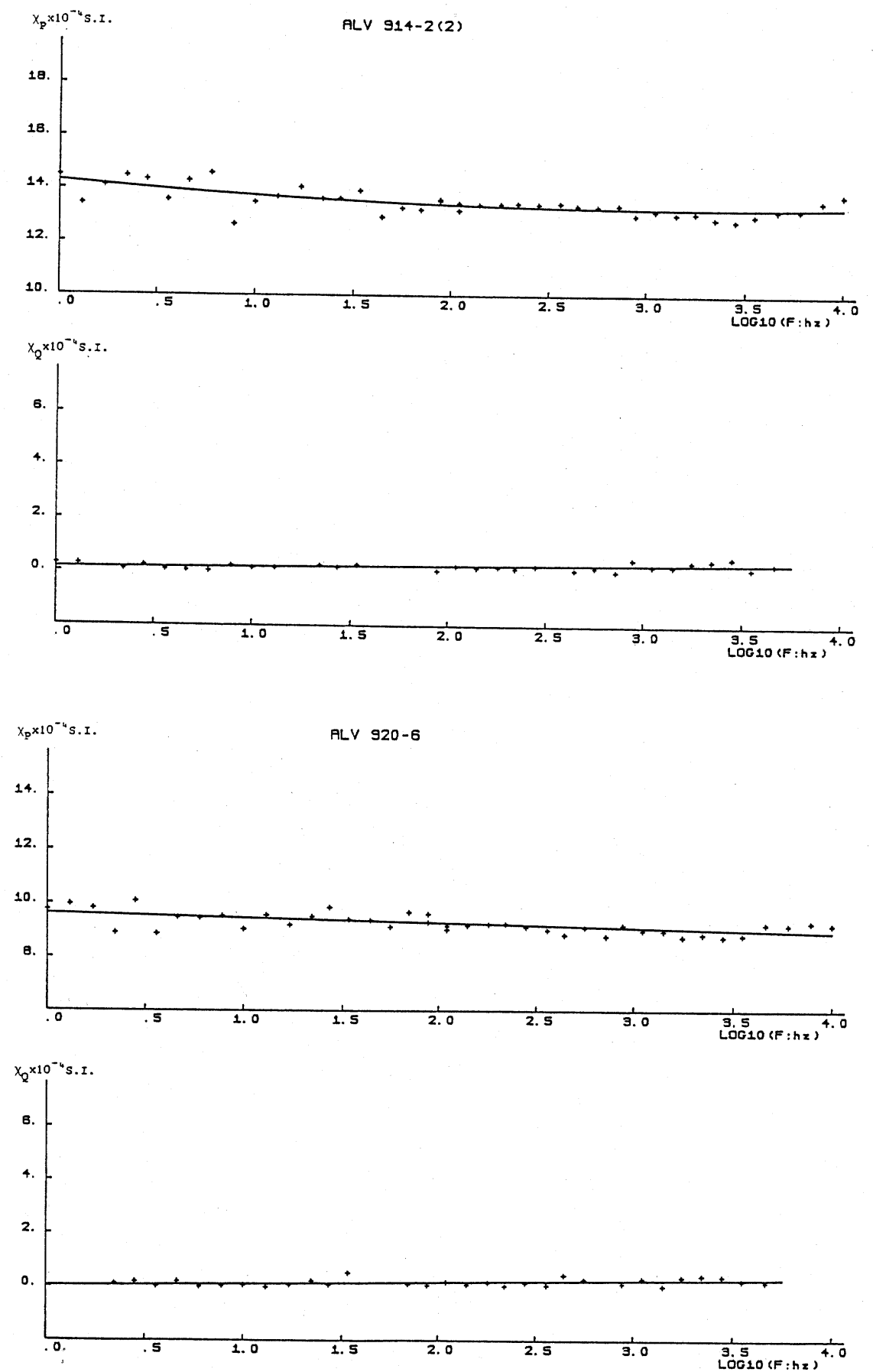

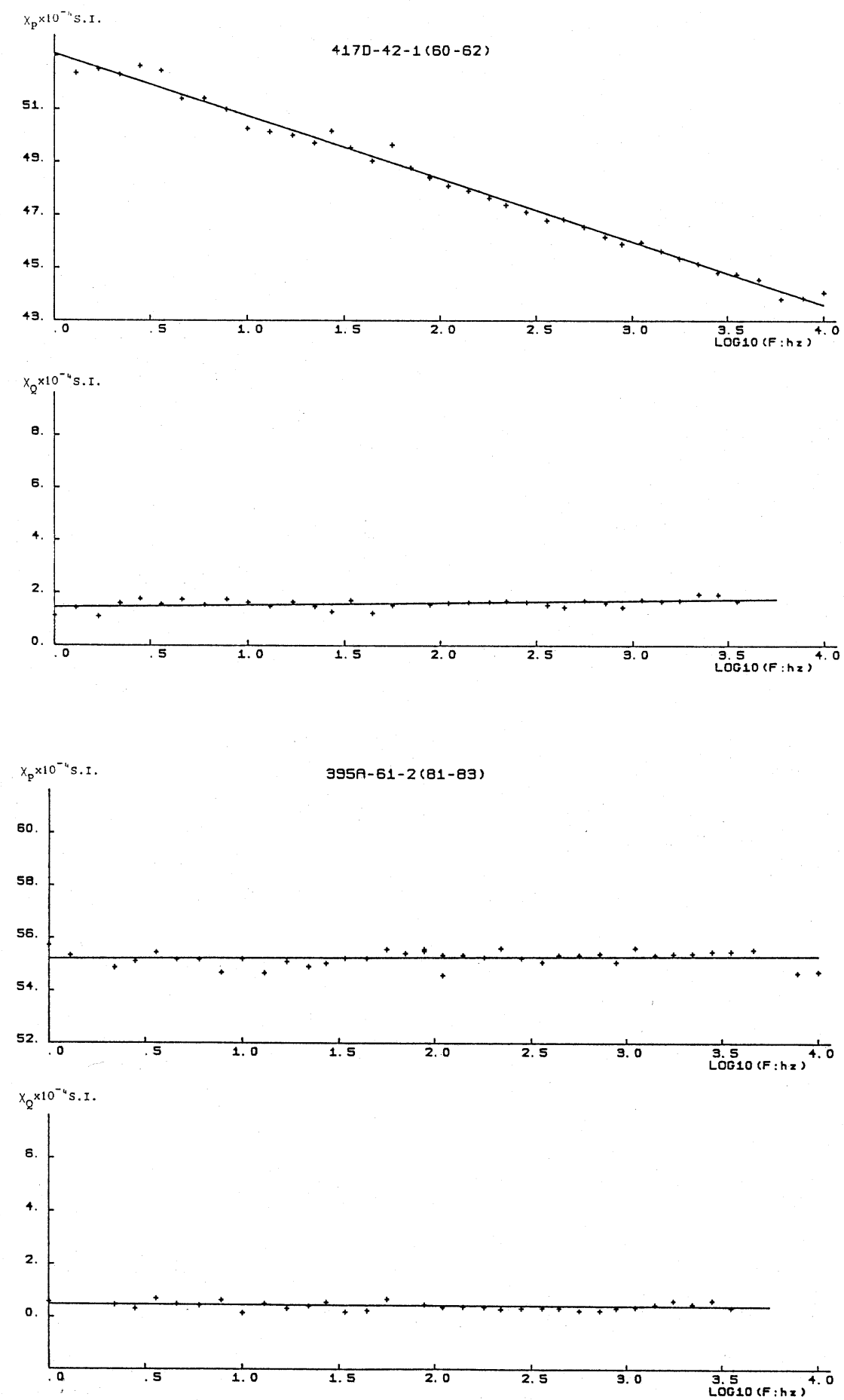

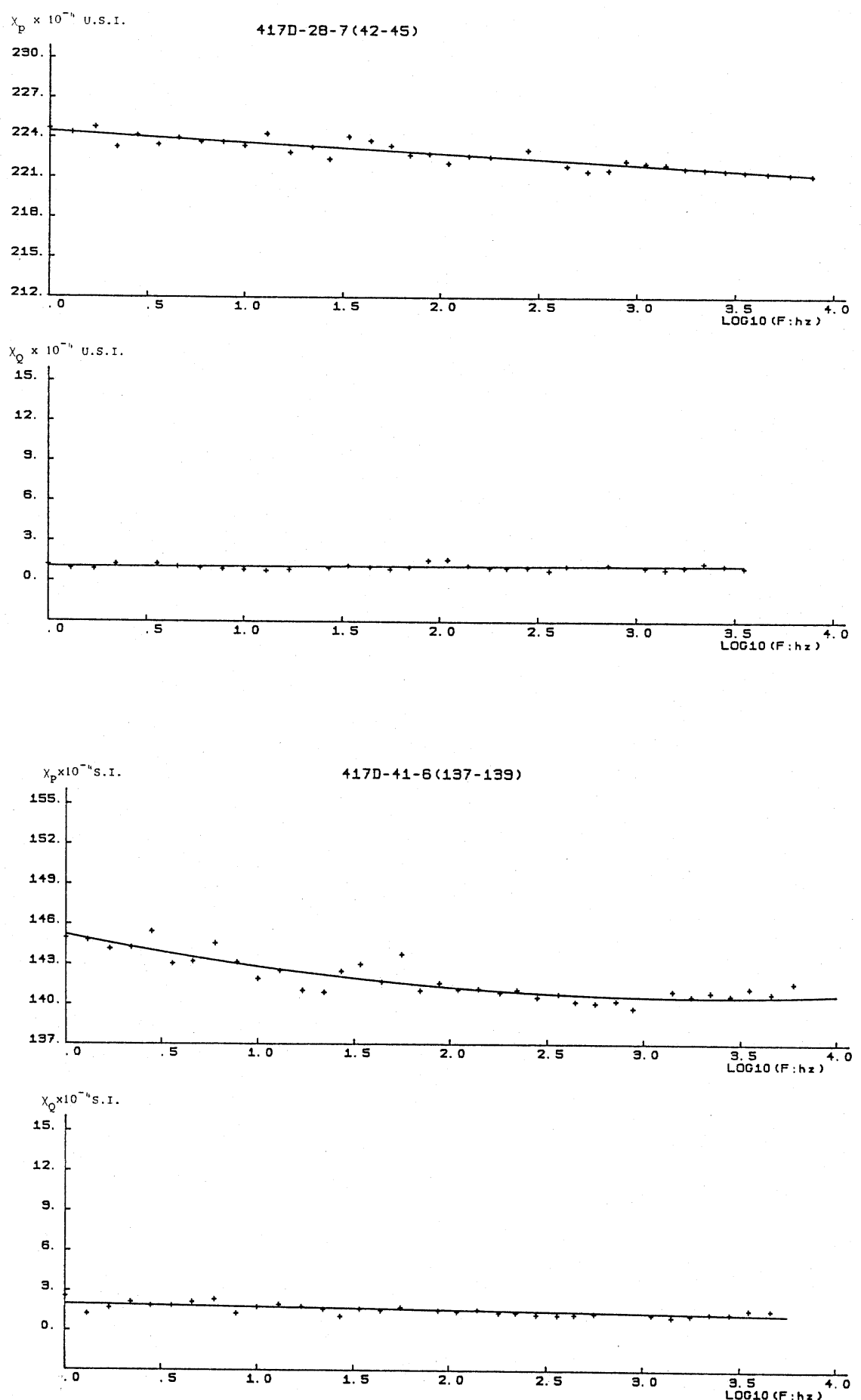


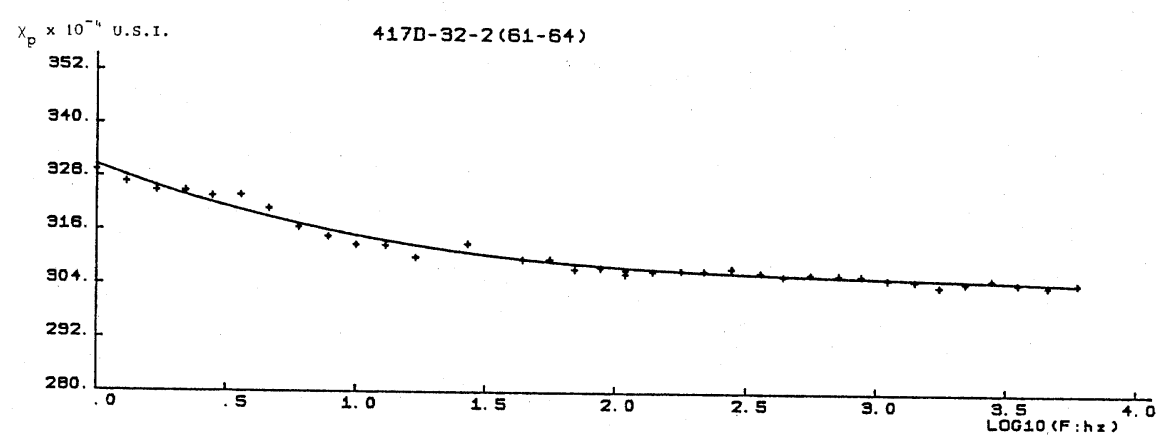
$x_{2} \times 10^{-4}$ U.s.r.
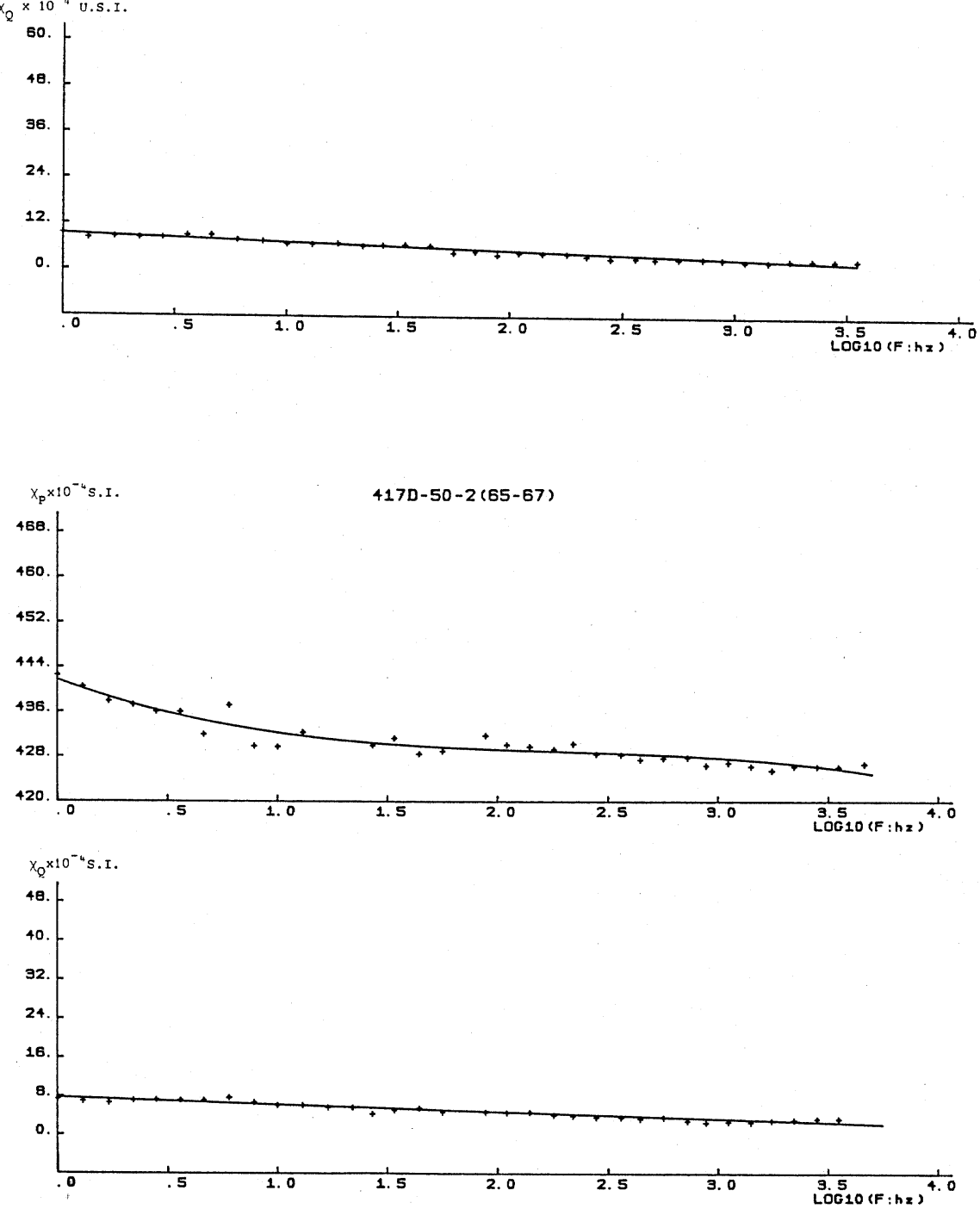
Appendix 2. Theoretical Calculation of the Quadrature Susceptibility in Rayleigh Domain

1) Very fine (single domain) independent grains

Developing NÉEL's calculation (1949) for a weak alternative field, MULLINS and TITE (1973) consider the magnetization $J$ of one grain of time constant $\tau_{0}$. For $h=h_{0} \sin \omega t$, $J$ being the solution of $\tau_{0}(\mathrm{~d} J / \mathrm{d} t)+J=J_{0}$, they obtained

$$
J=\frac{J_{0} \sin \omega t}{1+\omega^{2} \tau_{0}^{2}}-\frac{J_{0} \omega \tau_{0} \cos \omega t}{1+\omega^{2} \tau_{0}^{2}}
$$

$J_{0}$ being the moment that would be taken by the grain after and infinite time in constant field $h_{0}$.

By integration between $\tau_{0} \simeq 1 \mathrm{~ns}$ and $\tau_{0} \rightarrow \infty$ they obtained

$$
\chi_{\mathrm{q}}=-\frac{\pi}{2} \cdot \frac{\partial \chi_{\mathrm{p}}}{\partial \log \omega}
$$

In his paper NÉEL (1949) reached the same result when calculating the energy lost by viscosity and linking it to the loss angle $\delta$ defined as the angle between the induction and the field. He got the formula

$$
\operatorname{tg} \delta=-\frac{\pi}{2} \cdot \frac{1}{\mu} \cdot \frac{\partial \mu}{\partial \log \omega}
$$

\section{2) Bulk magnetic materials}

In a following work NÉEL (1950) studied the magnetic viscosity corresponding to the displacement of the walls of domains induced by thermal fluctuations in massive multidomain bodies.

Calculating the energy lost in weak alternating field, he obtained again after removing losses due to eddy currents and hysteresis the same formula

$$
\frac{2}{\pi} \operatorname{tg} \delta=-\frac{1}{\mu_{\mathrm{r}}} \frac{\partial \mu_{\mathrm{r}}}{\partial \log \omega}
$$

\section{REFERENCES}

Bhathal, R. S. and F. D. STACEy, Frequency independence of low-field magnetic susceptibility of rocks, $J$. Geophys. Res., 74, 2025-2027, 1969.

Bleil, V. and B. Smith, Paleomagnetism of basalts, leg 51, Int. Rep. DSDP, U.S. Gvt. print off., Washington D.C., pp. 1351-1361, 1980.

Bloemendal, J., C. E. Barton, and C. Radhakrishnamurty, Correlation between Rayleigh Loops and frequency dependent and quadrature susceptibility: Application to magnetic granulometry of rocks, $J$. Geophys. Res., 90, 8759-8792, 1985.

DALY, L. and A. TABBAGH, Towards the in situ measurement of the remanent magnetization of oceanic basalts, Geophys. J., 95, 481-489, 1988. 
Heirtzler, J. R., G. O. Dickson, E. M. Herren, W. C. Pitman, and X. Le Pichon, Marine magnetic anomalies, geomagnetic field reversals and motions of the ocean floor and continents, J. Geophys. Res., 73, 2119-2136, 1968.

Johnson, H. P., Paleomagnetism of igneous rock samples, DSDP leg 45, Int. Rep. DSDP, U.S. Gvt. print off, Washington D.C., pp. 387-396, 1978.

Mullins, C. E. and M. S. Tite, Magnetic viscosity, quadrature susceptibility and frequency dependence of susceptibility in single-domain assemblies of magnetite and maghemite, J. Geophys. Res., 78, 804-809, 1973.

NÉEL, L., Théorie du traînage magnétique des ferromagnétiques en grains fins avec applications aux terres cuites, Ann. Géophys., 5, 99-136, 1949.

NÉEL, L., Théorie du traînage magnétique des substances massives dans le domaine de Rayleigh, Le Journal de Physique et le Radium, XI-2, 49-61, 1950.

Smith, B., Propriétés magnétiques des roches basaltiques provenant de la couche 2 de la croûte océanique. Effects du degré de cristallisation et de l'altération basse température, Thèse, Université PARIS VI, 1984.

Trigul, M., Etude des susceptibilités magnétiques en champ alternatif et continu de carottes de la croûte océanique en vue de l'interprétation des diagraphies électromagnétiques et magnétiques, Thèse, Université PARIS VI, 1987.

VINCENZ, S. A., Frequency dependence of magnetic susceptibility of rock in weak alternating fields, J. Geophys. Res., 70, 1371-1377, 1965. 